\title{
High-Efficiency Production of Large-Size Few-Layer Graphene Platelets via Pulsed Discharge of Graphite Strips
}

\author{
Xin Gao ${ }^{1,2}$, Tomomasa Hiraoka ${ }^{2}$, Shunsuke Ohmagari ${ }^{2}$, Shigeru Tanaka ${ }^{2}$, Zemin Sheng ${ }^{3}$, \\ Kaiyuan Liu ${ }^{3}$, Meng $\mathrm{Xu}^{3}$, Pengwan Chen ${ }^{1, *}$ and Kazuyuki Hokamoto ${ }^{2, *}$ (1) \\ 1 State Key Laboratory of Explosion Science and Technology, Beijing Institute of Technology, \\ Beijing 100081, China; rich.c.gao0522@163.com \\ 2 Institute of Pulsed Power Science, Kumamoto University, Kumamoto 860-8555, Japan; \\ 176d8552@st.kumamoto-u.ac.jp (T.H.); 198d8454@st.kumamoto-u.ac.jp (S.O.); \\ tanaka@mech.kumamoto-u.ac.jp (S.T.) \\ 3 School of Material Science and Engineering, Beijing Institute of Technology, Beijing 100081, China; \\ zmshengbit@163.com (Z.S.); 13121164743@163.com (K.L.); xumeng@bit.edu.cn (M.X.) \\ * Correspondence: pwchen@bit.edu.cn (P.C.); hokamoto@mech.kumamoto-u.ac.jp (K.H.)
}

Received: 22 November 2019; Accepted: 11 December 2019; Published: 16 December 2019

\begin{abstract}
The synthesis of large-size graphene materials is still a central focus of research into additional potential applications in various areas. In this study, large-size graphene platelets were successfully produced by pulsed discharge of loose graphite strips with a dimension of $2 \mathrm{~mm} \times 0.5 \mathrm{~mm} \times 80 \mathrm{~mm}$ in distilled water. The graphite strips were made by pressing and cutting well-oriented expanded graphite paper. The recovered samples were characterized by various techniques, including TEM, SEM, optical microscopy (OM), atomic force microscopy (AFM), XRD and Raman spectroscopy. Highly crystalline graphene platelets with a lateral dimension of 100-200 $\mu \mathrm{m}$ were identified. The high yield of recovered graphene platelets is in a range of $90-95 \%$. The results also indicate that increasing charging voltage improves the yield of graphene platelets and decreases the number of graphitic layers in produced graphene platelets. The formation mechanism of graphene platelets was discussed. This study provides a one-step cost-effective route to prepare highly crystalline graphene platelets with a sub-millimeter lateral size.
\end{abstract}

Keywords: graphene; large size; pulsed wire discharge; graphite strip

\section{Introduction}

Graphene, firstly synthesized by Noveselov et al. [1] in 2004, has been proved as a wonderful future material with plenty of applications [2-8]. As a typical two-dimensional material, its particular atom-thick graphitic layer structure consisting of carbon atoms packed into a honeycomb lattice possesses various unique properties compared with other carbon nanomaterials [9], including outstanding thermal transport property [10,11], superconductivity [12,13], mechanical properties [5,6,14], optical properties [15,16], electronic properties [1,4,17], etc. A great deal of research has suggested multiple applications of graphene in areas such as field effect transistors [1,18], sensors [19,20], metal-free electrodes [21,22], energy storage [23], biomedical applications [24], etc. In addition, the applications of graphene materials also depend on their specific morphology [4,23], lateral dimension [25-27], and quality $[25,27]$. In much of the research conducted on graphene, one central focus is to synthesize large-size graphene materials for a higher potential application in the areas of electronics, solar energy devices, and mechanical structures [28-30]. For example, Ruse et al. [25] demonstrated that graphene 
with a large size increases the hydrogen storage of $\mathrm{Mg} /$ graphene nanocomposite by bridging $\mathrm{Mg}$ nanoparticles. Xu et al. [29] also employed the graphene at a size of $50 \mu \mathrm{m}-1 \mathrm{~mm}$ grown on Ni film substrate to improve the light transmittance in the mid-infrared (MIR) bandwidth of HgCdTe infrared detector with low cost. Additionally, Zhang et al. [31] synthesized large area uniform graphene film consisting of 1-30 $\mathrm{mm}$ graphene platelets to replace indium tin oxide (ITO) as flexible, transparent conductive film.

Various methods have been reported to synthesize graphene materials [9,32-36] including mechanical exfoliation method, oxidation reduction method, chemical vapor deposition (CVD) method, liquid-phase exfoliation method, arc-discharge method, electrochemical exfoliation method, detonation method, pulsed wire discharge method, interlayer catalytic exfoliation, etc. Among them, several methods, including oxidation reduction method, CVD method, and interlayer catalytic exfoliation, have been reported to prepare large-size graphene. Su et al. [37] obtained ultra large single-layer reduced graphene oxide (up to millimeter size) using oxidation reduction method (Hummer's method). In this study, natural graphite flakes with an average size of 3-5 $\mathrm{mm}$ were oxidized by a mixture of concentrated $\mathrm{H}_{2} \mathrm{SO}_{4}, \mathrm{P}_{2} \mathrm{O}_{5}$ and $\mathrm{K}_{2} \mathrm{~S}_{2} \mathrm{O}_{8}$, exfoliated by stirring with addition of $\mathrm{KMnO}_{4}$, and then reduced using hydrazine monohydrate to form large-size graphene. Through CVD method, the wafer-scale graphene was also synthesized [38] on different metal substrates, using the deposition of carbon atoms from $\mathrm{CH}_{4}$ or $\mathrm{C}_{2} \mathrm{H}_{4}$ gases at high temperatures $\left(800-1077^{\circ} \mathrm{C}\right)$. Bae et al. [39] synthesized 30-inch graphene films using the same method. With respect to interlayer catalytic exfoliation method, Geng et al. [28] employed $\mathrm{FeCl}_{3}$-intercalated graphite mixed with $30 \% \mathrm{H}_{2} \mathrm{O}_{2}$ in a reactive bottle for $2 \mathrm{~h}$ to exfoliate the graphitic layers to form graphene in a size of $40 \times 60 \mu \mathrm{m}^{2}$ with scalable production. However, till now, a great challenge has remained in realizing large-quantity and high-quality production of large-size graphene materials for further industrialization.

Pulsed wire discharge (electrical wire explosion) employs a high-density current to heat a thin conductive wire, leading to rapid melt and vaporization of the wire at high temperature and pressure [40]. Subsequently, the ultra-hot products scatter out rapidly along a shockwave, and then cool down in the medium to form nanoparticles. Thus, the whole process of pulsed wire discharge, whose duration is in nano- or micro-seconds, can be divided into two processes, joule heating process and subsequent explosion process [35]. The wire types, media and the energy input adjusted by charging voltage are the main factors influencing the joule heating process of pulsed wire discharge [35,40-42], providing a one-step cost-effective route to synthesize nanoparticles. Various nanomaterials have been synthesized through this method, including metal nanopowders, metal compound nanopowders, nanocomposite materials, and multiple carbon nanomaterials. For example, Liu et al. [41] reported the synthesis of Al nanoparticles by pulsed discharge of Al wire in an Argon medium. Wada et al. [42,43] obtained $\mathrm{TiO}_{2}$ and TiN nanopowders using the pulsed discharge of Ti wire in air and liquid nitrogen, respectively. Tanaka et al. [44] have recovered tungsten carbide nanoparticles after the pulsed discharge to tungsten wire in liquid paraffin. He et al. [45] synthesized boron nitride nanosheet/nanotube-Fe nanocomposite via pulsed discharge of iron wire coated by boron nitride powder. Furthermore, several metal/metal oxide/graphene nanocomposites were also prepared through pulsed discharge of different metal wires in graphene oxide suspension [46,47]. In addition, several reports have been documented to use pulsed wire discharge to synthesize carbon nanomaterials, including fullerene $[48,49]$, carbon nanotube [50,51], and amorphous carbon [52]. However, the synthesis of graphene materials with a sub-millimeter lateral size using pulsed wire discharge has rarely been reported.

In our previous study, a graphite stick was connected to electrodes for pulsed discharge to prepare mono-layer and few-layer graphene in distilled water [35]. Through delicate control of energy input, the graphitic layers in as-prepared graphene materials can be generally controlled. The lateral size of recovered graphene materials was $0.5-5 \mu \mathrm{m}$, determined by the initial size of graphite particles in the raw graphite stick. In this study, we demonstrate a one-step route with high yield to prepare few-layer graphene platelets (FLGP) with a lateral dimension of 100-200 $\mu \mathrm{m}$ through pulsed discharge of thin graphite strips made of well-oriented expanded graphite paper. 


\section{Materials and Methods}

\subsection{Sample Prepararion}

To recover the as-prepared samples, a cylindrical stainless steel explosion chamber (Figure 1a) with an inner diameter of $200 \mathrm{~mm}$ and a depth of $300 \mathrm{~mm}$ was designed. The chamber consists of a lid and a cylindrical container. Two copper electrodes wrapped with insulation blocks were installed with the lid and connected to a capacitor with a capacitance of $12.5 \mu \mathrm{F}$. The capacitor connected to electrodes could be charged by a power supply to certain voltages $(0-40 \mathrm{kV})$ to control the stored energy. The discharge process was controlled by an air switch in the discharge circuit. Expanded graphite paper was pressed and cut to obtain graphite strips with a dimension of $2 \mathrm{~mm} \times 0.5 \mathrm{~mm} \times 80 \mathrm{~mm}$ and a mass of $0.113 \mathrm{~g}$ (Figure 1b). The graphite strip was fixed to the two copper electrodes for pulsed discharge. Then $5 \mathrm{~L}$ distilled water was poured into the chamber to immerse the graphite strip. After pulsed discharge, the black aqueous mixture (Figure 1c) was collected in a glass bottle, then dried to remove all the water for further characterization.
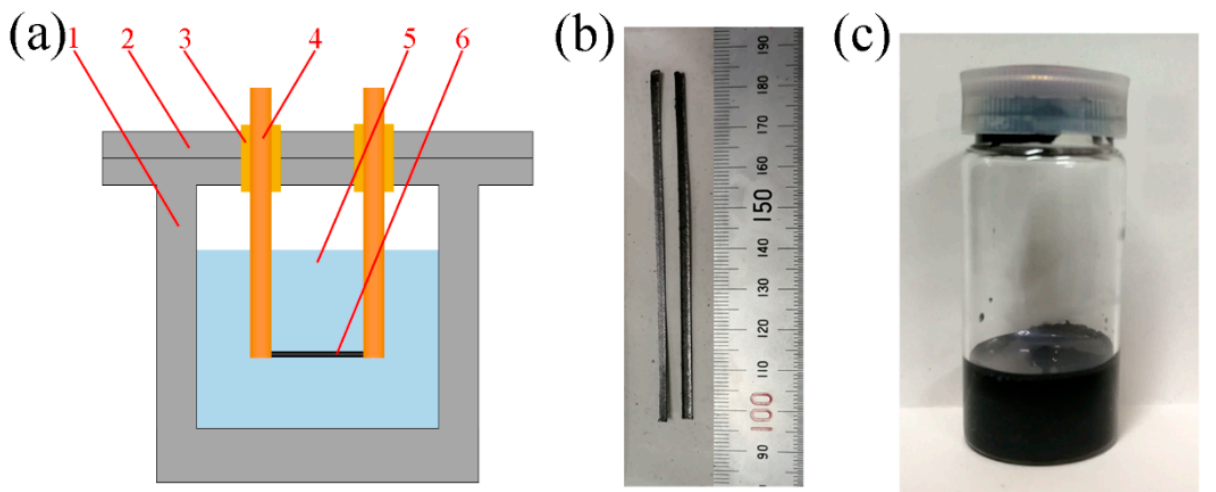

Figure 1. (a) Schematic diagram of pulsed wire chamber, 1-cylindrical stainless steel container, 2-lid, 3-insulator, 4-copper electrodes, 5-distilled water, 6-graphite wire, photographs of (b) graphite strip, and (c) recovered suspension of No. 3 sample.

\subsection{Characterizations}

The morphology and microstructure of as-prepared samples were examined by optical microscopy (OM, Nikon LM 2), and analyzed by field emission scanning electron microscopy (SEM, JEOL JSM 6510A) and high resolution transmission electron microscopy (HRTEM, FEI Tecnai G² F20 S-Twin). Raman spectra of the raw graphite strip and recovered samples were recorded on a LabRAM Aramis Raman spectrometer with a He-Ne laser at an excitation wavelength of $633 \mathrm{~nm}$. The corresponding XRD patterns were recorded on an X-ray diffractometer (XRD) (Rigaku Ultima IV multipurpose XRD system) with $\mathrm{Cu} \mathrm{K} \alpha$ radiation $(\lambda=0.15406 \mathrm{~nm})$ at a step size of $0.05^{\circ}(2 \theta)$ and a step scan time of $1.0 \mathrm{~s}$. The sample suspensions were dropped on a Si plate and dried at room temperature for optical microscopic, SEM and Raman spectroscopic analysis. The sample suspensions were also dropped and dried on a copper mesh grid for TEM analysis. The atomic force microscopy (AFM) analysis was taken by MFP-3D Infinity AFM.

\section{Results}

The experimental conditions of pulsed discharge of graphite strips are listed in Table 1, including the charging voltage and the energy stored in the capacitor. Three charging voltages (20,30, and $40 \mathrm{kV})$ were selected for pulsed discharge experiments. Moreover, the graphene yields for these experiments are calculated by measuring the mass of the recovered graphene and initial graphite strip. The yield results are listed in Table 1. 
Table 1. Experimental conditions and characterization of pulsed discharge of graphite strips *.

\begin{tabular}{cccccccc}
\hline No. & $\mathbf{U}(\mathbf{k V})$ & $\mathbf{E}(\mathbf{J})$ & $\begin{array}{c}\text { 2D Band } \\
\left(\mathbf{c m}^{-\mathbf{1}}\right)\end{array}$ & $\mathbf{I}_{\mathbf{2 D}} / \mathbf{I}_{\mathbf{G}}$ & $\mathbf{I}_{\mathbf{D}} / \mathbf{I}_{\mathbf{G}}$ & $\mathbf{I}_{\mathbf{D}} / \mathbf{I}_{\mathbf{D}^{\prime}}$ & Yield \\
\hline Raw & - & - & 2684 & 0.29 & 0.17 & 3.58 & - \\
1 & 20 & 2500 & 2673 & 0.70 & 0.15 & 3.69 & $90 \%$ \\
2 & 30 & 5625 & 2665 & 0.91 & 0.19 & 2.89 & $92 \%$ \\
3 & 40 & 10,000 & 2662 & 1.03 & 0.20 & 2.88 & $95 \%$ \\
\hline
\end{tabular}

* $\mathrm{U}$ is the charging voltage, $\mathrm{E}$ is the stored energy in the capacitor, $\mathrm{I}_{2 \mathrm{D}} / \mathrm{I}_{\mathrm{G}}, \mathrm{I}_{\mathrm{D}} / \mathrm{I}_{\mathrm{G}}$, and $\mathrm{I}_{\mathrm{D}} / \mathrm{I}_{\mathrm{D}^{\prime}}$ are the intensity ratios of $2 \mathrm{D}$ band to $\mathrm{G}$ band, $\mathrm{D}$ band to $\mathrm{G}$ band, and $\mathrm{D}$ band to $\mathrm{D}^{\prime}$ band of Raman spectra, respectively.

Figure 2 shows the microstructures of the recovered samples examined by TEM and HRTEM. The results of typical TEM images show the presence of ultra-thin wrinkled and extended carbon films with an interlayer distance of $0.3-0.4 \mathrm{~nm}$. Based on the numbers of graphitic layers in the above films, the recovered samples are identified as a mixture of mono-layer graphene and FLGP. When the charging voltage was $20 \mathrm{kV}$ (No. 1 sample), the recovered sample mainly contained FLGPs with 3-7 graphitic layers. As the charging voltage increased to $30 \mathrm{kV}$ (No. 2 sample), the main component was few-layer graphene consisting of $2-5$ graphitic layers. When the charging voltage further increased to $40 \mathrm{kV}$ (No. 3 sample), the recovered sample exhibited a mixture of mono-layer graphene and FLGPs with $2-4$ graphitic layers. The results imply that the increase of charging voltage is conducive to produce FLGPs with less layers. Furthermore, the selected area electron diffraction (SAED) patterns of all three samples display hexagonally arranged diffraction spots, which is in accordance with the typical results of highly crystalline graphene.

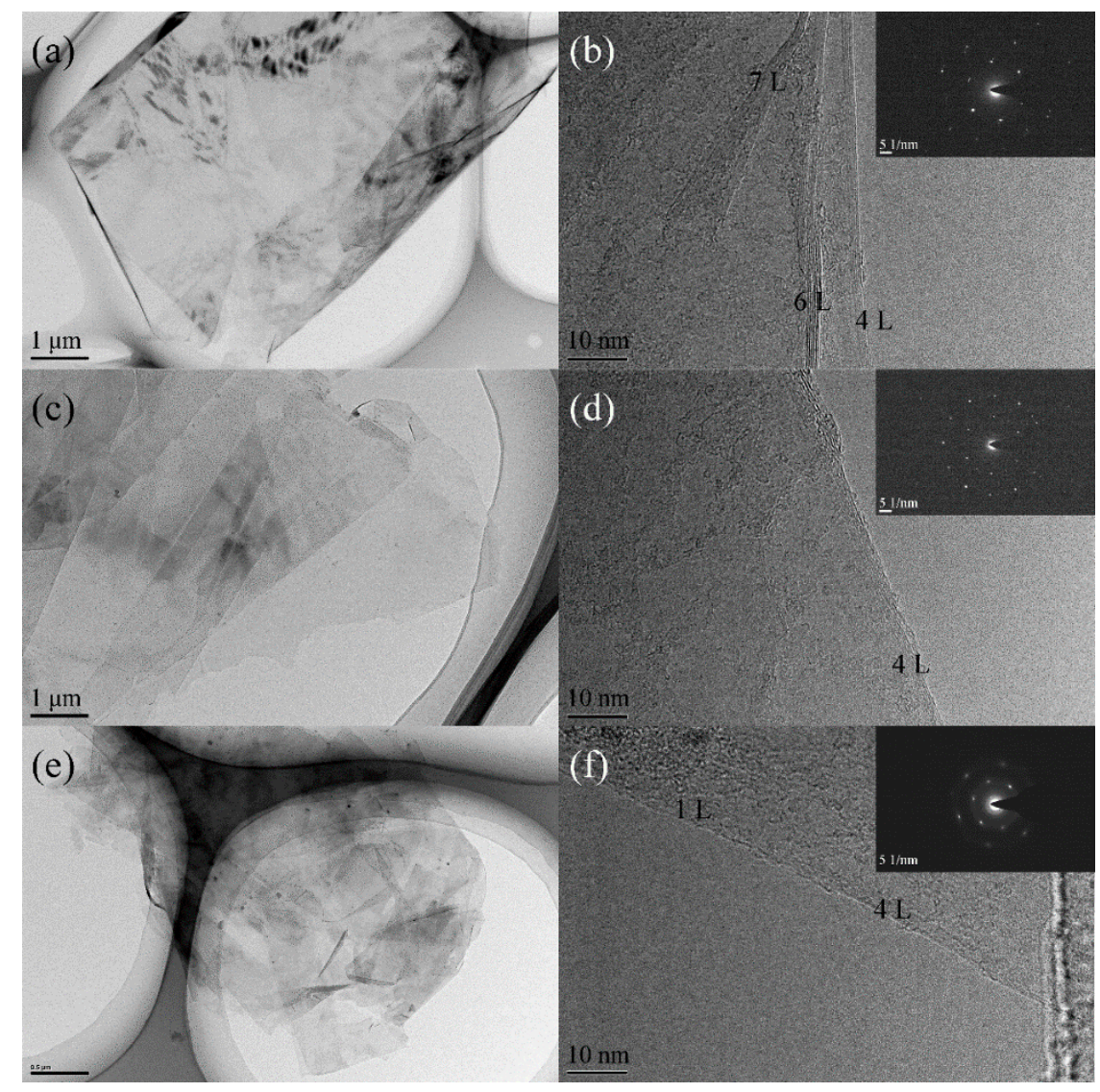

Figure 2. (a) TEM and (b) HRTEM images of No. 1 sample, (c) TEM and (d) HRTEM images of No. 2 sample, (e) TEM and (f) HRTEM images of No. 3 sample. The insets of (b), (d), and (f) show the selected area electron diffraction (SAED) patterns of Nos. 1-3 samples, respectively. 
Figure 3a shows the cross sectional microstructure of raw graphite strips, indicating a layered structure consisting of quantities of graphitic layers. Figure $3 b-d$ show typical SEM and higher-magnification SEM images, respectively, demonstrating the presence of curved and extended ultra-thin carbon films which is the typical morphology of graphene [28,53-55]. The curved structure is owing to thermodynamically instability of the two dimensional materials [56]. The statistics of SEM examinations show the size of produced FLGPs is in a range of 100-200 $\mu \mathrm{m}$, which is much larger than that $(0.5-5 \mu \mathrm{m})$ of graphene nanosheets prepared by pulsed discharge of graphite sticks.

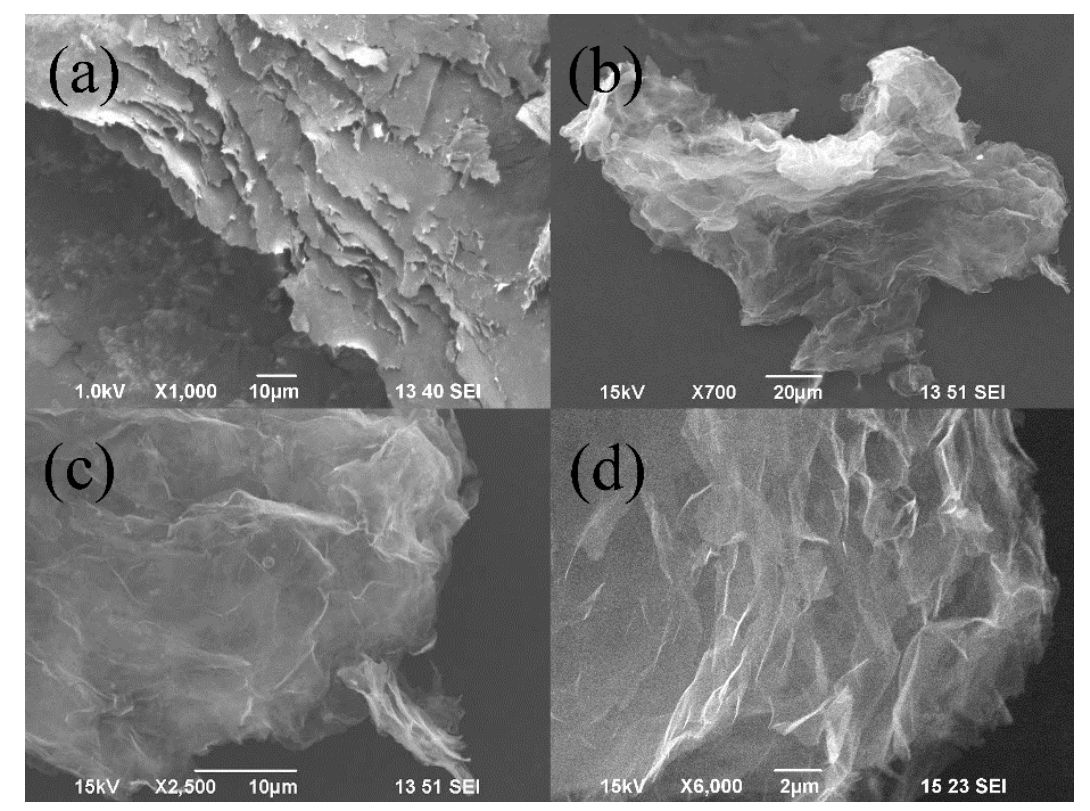

Figure 3. (a) SEM image of the cross section of the raw graphite strip, (b) SEM, and (c), (d) higher magnification SEM images of No. 3 sample, respectively.

Furthermore, the OM images of samples No. 1 and 3 (Figure 4a,b) show the transparent FLGPs with wrinkles and folds, which is similar to the morphology of the OM results of graphene which were also reported by Escobar-Alarcon et al. [57] and Lee et al. [58]. The statistical results of OM images also show the lateral sizes of produced FLGPs in samples No. 1-3 are in a range of 100-200 $\mu \mathrm{m}$. It implies that the charging voltage has little influence on the lateral size of produced FLGPs produced by pulsed discharge. In addition, Figure 4c shows the typical AFM topography image of sample No. 1, revealing the presence of ultra-thin carbon films with a size of $100 \mu \mathrm{m}$. Figure $4 \mathrm{~d}$ shows a higher magnification image of the carbon film with the height profile along the red line. The height result is in a range of 2.7-3.1 nm, which most probably corresponds to the thickness of 5-7 layer graphene, considering the thickening phenomenon due to tip-graphene electrostatic force, physisorbed water, etc. $[59,60]$ The thickness and size of FLGP obtained by AFM are in good agreement with those obtained by HRTEM, SEM, and OM. 

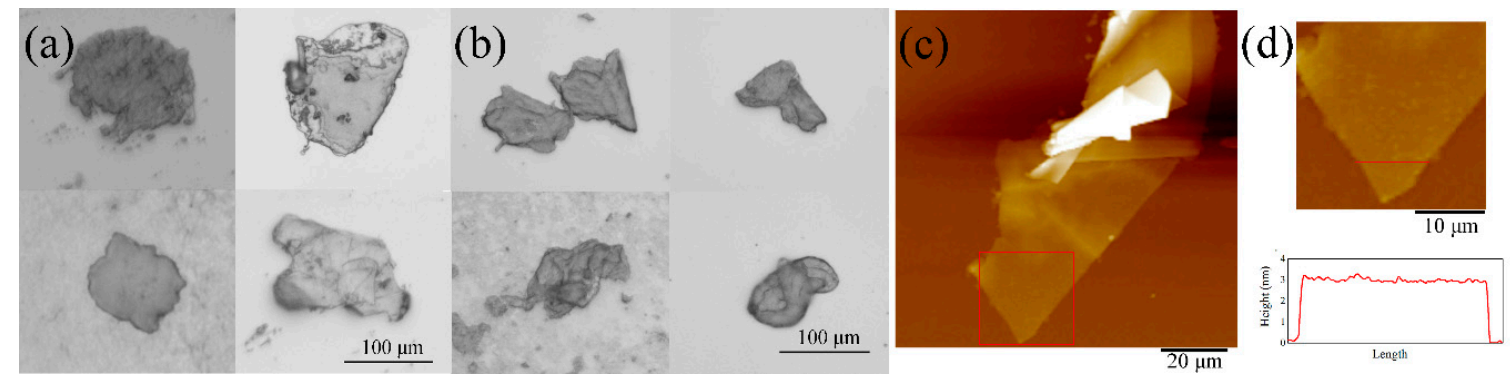

Figure 4. OM images of (a) sample No. 1 and (b) sample No. 3, (c) and, (d) AFM topography images of sample No. 1, respectively. (d) also shows the height profile in of the few-layer graphene platelets (FLGP) along the red line.

Figure 5a shows the XRD patterns of the raw graphite strip and the recovered samples. The XRD pattern of raw graphite strip shows only two characteristic peaks, one strong peak appearing at $26.5^{\circ}$ assigned to graphite (002) diffraction with a weak peak at $54.5^{\circ}$ assigned to graphite (004) diffraction, indicating the interlayer distance of graphitic layers with high crystallinity. The absence of (101) diffraction at $44.4^{\circ}$ in the XRD pattern reveals good orientation of raw graphite strips. While in the XRD patterns of recovered samples, only a weak diffraction peak is observed at 26.2-26.4 (inset of Figure 5a), assigned to graphene (002) diffraction, demonstrating the existence of FLGPs produced by pulsed discharge. The calculated d values corresponding to the (002) peaks of recovered samples are in range of $0.337-0.340 \mathrm{~nm}$ based on Bragg's law. The results are slightly larger than the d values of graphite $(0.335 \mathrm{~nm})$, also in a good agreement with the TEM results and the previous reports [22,59].
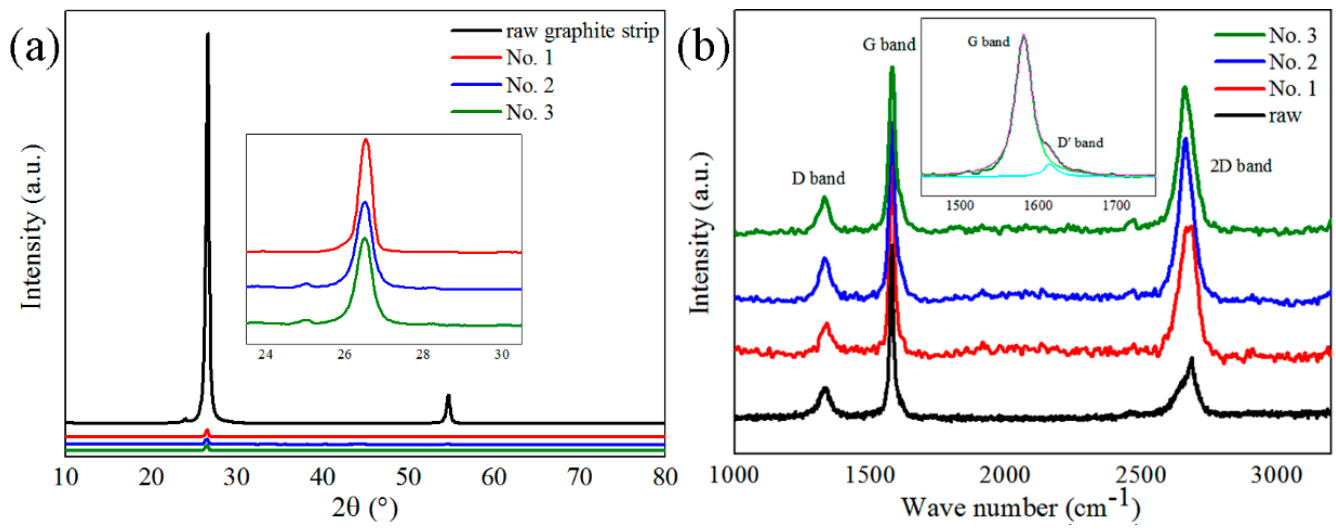

Figure 5. (a) XRD patterns and (b) Raman spectra of the raw graphite strip and recovered samples.

Figure $5 \mathrm{~b}$ shows the Raman spectra of the raw graphite strip and recovered samples, providing a quick and simple structural and quality characterization of above carbon materials. Four typical Raman bands of carbon materials are observed in Figure $5 b$, including D band $\left(1332 \mathrm{~cm}^{-1}\right), G$ band $\left(1581 \mathrm{~cm}^{-1}\right)$, $\mathrm{D}^{\prime}$ band $\left(1617 \mathrm{~cm}^{-1}\right.$, as shown in inset of Figure $5 \mathrm{~b}$ ), and $2 \mathrm{D}$ band (in a range of $2662-2688 \mathrm{~cm}^{-1}$ ). The $2 \mathrm{D}$ band has been widely used to distinguish mono-layer graphene and few-layer graphene from graphite $[60,61]$. A higher value of $\mathrm{I}_{2 \mathrm{D}} / \mathrm{I}_{\mathrm{G}}$ indicates less graphitic layers $[54,56]$ in produced FLGPs. The $\mathrm{I}_{\mathrm{D}} / \mathrm{I}_{\mathrm{G}}$ value is used to characterize the disorder degree of the graphitic layers $[61,62]$. The $\mathrm{I}_{\mathrm{D}} / \mathrm{I}_{\mathrm{D}^{\prime}}$ reveals the disorder type of graphene [63].

The above intensity ratio values of the raw graphite strip and the recovered samples are listed in Table 1 . The $\mathrm{I}_{2 \mathrm{D}} / \mathrm{I}_{\mathrm{G}}$ values of the recovered samples were $0.70-1.03$, much larger than that of the raw graphite strip (0.29), indicating that the recovered samples were few-layer graphene [54,56]. Moreover, when the charging voltage was increased from $20 \mathrm{kV}$ to $30 \mathrm{kV}$ and $40 \mathrm{kV}$, the $\mathrm{I}_{2 \mathrm{D}} / \mathrm{I}_{\mathrm{G}}$ value increased from 0.70 to 0.91 and 1.03 accordingly, indicating that increasing the charging voltage can decrease the number of graphitic layers of produced graphene. Additionally, the 2D band position also revealed the 
thickness of the graphene materials [64]. In Figure 5b, as the charging voltage was increased from $20 \mathrm{kV}$ to $40 \mathrm{kV}$, a slight redshift of the $2 \mathrm{D}$ band from $2673 \mathrm{~cm}^{-1}$ to $2662 \mathrm{~cm}^{-1}$ was observed, revealing that the graphitic layers in FLGPs are less when the charging voltage is higher. The results of the influence of charging voltage on graphene layers is in good agreement with the TEM results. In addition, all the $\mathrm{I}_{\mathrm{D}} / \mathrm{I}_{\mathrm{G}}$ values of recovered samples are in a range of $0.15-0.20$ similar to that of the raw graphite strip (0.17), suggesting that the disorder degree of the recovered samples and the raw graphite strip are nearly the same. Thus, the pulsed discharge process in our experiments can hardly generate structural defects. Furthermore, the above $\mathrm{I}_{\mathrm{D}} / \mathrm{I}_{\mathrm{G}}$ values are also smaller than those of graphene produced by arc discharge method (ca. 1.0) [65], oxidation reduction method (ca. 1.0) [37,66,67], and electrochemical exfoliation method (ca. 0.42) [68], showing higher crystallinity of FLGPs produced by pulsed discharge. The $\mathrm{I}_{\mathrm{D}} / \mathrm{I}_{\mathrm{D}^{\prime}}$ values of the recovered samples were in the range of 2.88-3.69, close to 3.5, suggesting that the main disorder in the raw material and formed FLGPs is boundary-like disorder [63]. It also indicates that the action of pulsed discharge can barely lead to the vacancy defects, in which the $\mathrm{I}_{\mathrm{D}} / \mathrm{I}_{\mathrm{D}^{\prime}}$ is close to 7 [63]. Raman results are in good agreement with those of TEM and XRD analysis.

The yields of produced FLGPs under different conditions are listed in Table 1, demonstrating a high yield of $90-95 \%$, which is much higher than those of many other methods, such as pulsed discharge of graphite sticks (40-50\%) [35], arc-discharge method (10-20\%) [65], liquid phase exfoliation (7-51\%) [69], several mechanical exfoliation methods [33], etc. The yield results also indicate that the increase of charging voltage from $20 \mathrm{kV}$ to $30 \mathrm{kV}$ and $40 \mathrm{kV}$ improves the yield of produced FLGPs from $90 \%$ to $92 \%$ and $95 \%$, respectively.

\section{Discussion}

Based on the above characterization results, we propose the mechanism regarding the formation of FLGPs using pulsed discharge (as shown in Figure 6) which is similar to those of pulsed discharge of graphite sticks and thermal exfoliation method. During the joule-heating process of pulsed discharge, the rapid energy input leads to an environment of high temperature and high internal pressure. Under the action of high temperature and high internal pressure, the graphitic layers in well-oriented graphite strips overcome the constraints of Van der Waals force and $\pi-\pi$ interaction, and are exfoliated easily to form FLGPs. After exfoliation, the formed FLGPs are separated in the distilled water medium due to the rapid expansion during explosion process, which prevents the stacking and agglomeration of formed FLGPs from Van der Waals force. Thus, the FLGP suspension is obtained.

However, note that the graphite strip in these experiments is a well-oriented graphite material, in which the lateral dimension of graphitic layers is in sub-millimeter scale, rather than the graphite stick consisting of micro graphite particles with randomly-distributed orientation. Since the expansion direction of graphitic layers is approximately along the z-axis of graphite crystallites and vertical to the surface of graphite strips, the expansion of well-oriented graphite crystallites can be rarely inhibited by the expansion of adjacent crystallites. Consequently, the exfoliation efficiency of graphite strips is high. Moreover, the density of the graphite strip is approximately $1.4 \mathrm{~g} / \mathrm{cm}^{3}$, lower than the theoretical density of graphite $\left(2.26 \mathrm{~g} / \mathrm{cm}^{3}\right)$ and the density of the graphite stick $\left(1.9 \mathrm{~g} / \mathrm{cm}^{3}\right)$ in Ref 35 , implying a loose structure and high porosity of graphite strip. During pulsed discharge, under the sharp increase of temperature and pressure, the gas molecules in this loose material expand rapidly to exfoliate graphitic layers. Thus, both good orientation and the gas in the loose structure are conducive to the exfoliation under high temperature and high internal pressure, leading to a higher exfoliation efficiency of the graphite strip and a higher yield (90-95\%) of FLGPs.

The energy input during pulsed discharge is controlled to only cause the rapid thermal expansion effect to exfoliate graphitic layers without destroying the atomic structure of the graphitic layers, therefore the high crystallinity and large dimension of the original graphite crystallites in the graphite strips results in the high crystallinity and large lateral dimension (100-200 $\mu \mathrm{m})$ of the exfoliated FLGPs after pulsed discharge. In addition, a higher charging voltage increases the energy input during pulsed discharge, resulting in a higher temperature and internal pressure. Consequently, when the charging 
voltage is increased, the exfoliation efficiency is also increased to generate a slightly higher yield of FLGPs with less graphitic layers.

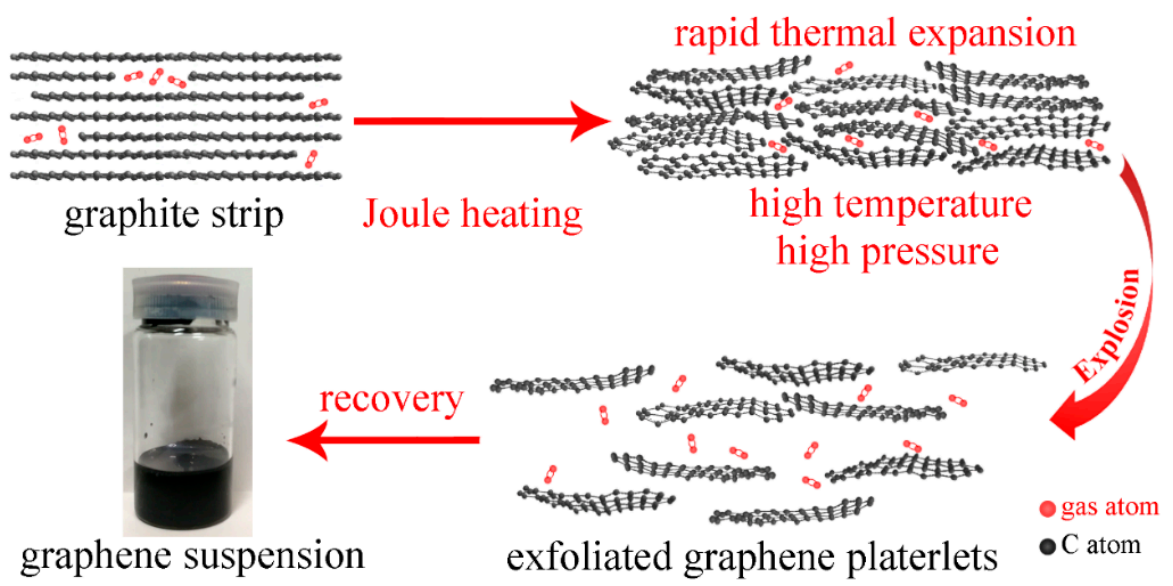

Figure 6. Schematic illustration of formation of FLGPs in pulsed discharge of graphite strips.

\section{Conclusions}

This study demonstrates an efficient, cost-effective and environmentally friendly route to produce highly crystalline large-size FLGPs in distilled water at room temperature.

The highly crystalline FLGPs with a lateral dimension of 100-200 $\mu$ m were produced successfully with a high yield of $90-95 \%$. The mechanism of graphene production is supposed to be the exfoliation of graphitic layers from a graphite strip under the action of joule heating induced by pulsed discharge. Two factors, charging voltage and the loose structure of the graphite strip, are critical to the exfoliation of graphitic layers and the exfoliation efficiency. As the increase of charging voltage from 20 to $40 \mathrm{kV}$, the yield of FLGPs is slightly increased with less graphitic layers owing to the higher exfoliation efficiency induced by higher internal pressure.

Additionally, the main cost of this experiment is the graphite strips cut from graphite paper with a cost of $\$ 22.8$ per kilogram (product from Jinglong Special Carbon Co., Ltd., Beijing, China), implying the great economical advantage of the synthetic route compared with the price of commercial graphene (e.g., graphene from Sigma-Aldrich, St. Louis, MO, USA (\$1191.1 per kilogram), etc.). Moreover, the experiments were carried out using graphite strips in distilled water without any other chemical agents, indicating that this route is environmentally friendly. Considering the high yield of this route and the large lateral dimension of produced graphene, this route could have a high potential in the areas of electronics, solar energy devices, and mechanical structures.

Author Contributions: Conceptualization, X.G. and P.C.; methodology, X.G., P.C. and K.H.; investigation, T.H., K.L. and M.X.; Data Curation, S.O. and Z.S.; writing-Original draft preparation, X.G. and P.C.; writing-Review and editing, X.G., S.T., and K.H.

Funding: This research was funded by the National Natural Science Foundation of China (Grant No. 11521062) and State Key Laboratory of Explosion Science and Technology, Beijing Institute of Technology (Grant No. ZDKT18-01).

Conflicts of Interest: The authors declare no conflict of interest.

\section{References}

1. Novoselov, K.S.; Geim, A.K.; Morozov, S.V.; Jiang, D.; Zhang, Y.; Dubonos, S.V.; Grigorieva, I.V.; Firsov, A.A. Electric field effect in atomically thin carbon films. Science 2004, 306, 666-669. [CrossRef] [PubMed]

2. Xu, Z.S.; Shi, X.L.; Zhai, W.Z.; Yao, J.; Song, S.Y.; Zhang, Q.X. Preparation and tribological properties of TiAl matrix composites reinforced by multilayer graphene. Carbon 2014, 67, 168-177. [CrossRef] 
3. Boparai,H.K.; Joseph, M.; Carroll, D.M.O. Cadmium $\left(\mathrm{Cd}^{2+}\right)$ removal by nano zerovalent iron: Surface analysis, effects of solution chemistry and surface complexation modeling. Environ. Sci. Pollut. Res. 2013, 20, 6210-6221. [CrossRef] [PubMed]

4. Son, Y.W.; Cohen, M.L.; Louie, S.G. Half-metallic graphene nanoribbons. Nature 2006, 444, 347-349. [CrossRef] [PubMed]

5. Cao, J.; Zhang, Y.Y.; Men, C.L.; Sun, Y.Y.; Wang, Z.N.; Zhang, X.T.; Li, Q.W. Programmable writing of graphene oxide/reduced graphene oxide fibers for sensible networks with in situ welded junctions. ACS Nano 2014, 8 , 4325-4333. [CrossRef]

6. Lee, C.; Wei, X.; Kysar, J.; Hone, J. Measurement of the elastic properties and intrinsic strength of monolayer graphene. Science 2008, 321, 385-388. [CrossRef]

7. Li, G.Y.; Zhang, X.T.; Wang, J.; Fang, J.H. From anisotropic graphene aerogels to electron- and photo-driven phase change composites. J. Mater. Chem. 2016, 4, 17042-17049. [CrossRef]

8. Jiang, M.; Wu, J.; Ren, Z.; Qi, M.; Bai, J.; Bai, Y.; Zhang, Y.; Wang, Q. Synthesis of graphene and its application as wide-band saturable absorbers. In Proceedings of the 12th IEEE Conference on Nanotechnology, Birmingham, UK, 20-23 August 2012; pp. 1-4. [CrossRef]

9. Rao, C.N.R.; Sood, A.K.; Subrahmanyam, K.S.; Govindaraj, A. Graphene: The new two-dimensional nanomaterial. Angew. Chem. Int. Ed. 2009, 48, 7752-7777. [CrossRef]

10. Tang, B.; Hu, G.X.; Gao, H.Y.; Hai, L.Y. Application of graphene as filler to improve thermal transport property of epoxy resin for thermal interface materials. Int. J. Heat Mass Transf. 2015, 85, 420-429. [CrossRef]

11. Xu, N.; Wang, B.L. Thermal property of bent graphene nanorribons. Eur. Phys. J. B 2015, 88, 123. [CrossRef]

12. Gonzalez, J. Kohn-Luttinger superconductivity in graphene. Phys. Rev. B 2008, 78, 205431. [CrossRef]

13. Cao, Y.; Fatemi, V.; Fang, S.A.; Watanabe, K.; Taniguchi, T.; Kaxiras, E.; Jarillo-Herrero, P. Unconventional superconductivity in magic-angle graphene superlattices. Nature 2018, 556, 43-50. [CrossRef]

14. Van der Zande, I.W.; McEuen, P.L. Mechanical properties of suspended graphene sheets. J. Vac. Sci. Technol. B 2007, 25, 2558-2561. [CrossRef]

15. Nair, R.P.; Blake, P.; Grigorenko, A.N.; Novoselov, K.S.; Booth, T.J.; Stauber, T.; Peres, N.M.; Geim, A.K. Fine structure constant defines visual transparency of graphene. Science 2008, 320, 1308. [CrossRef] [PubMed]

16. Wang, F.; Zhang, Y.B.; Tian, C.S.; Girit, C.; Zettl, A.; Crommie, M.; Shen, Y.R. Gate-variable optical transitions in graphene. Science 2008, 320, 206-209. [CrossRef] [PubMed]

17. Xia, J.L.; Chen, F.; Li, J.H.; Tao, N.J. Measurement of the quantum capacitance of graphene. Nat. Nanotechnol. 2009, 4, 505-509. [CrossRef] [PubMed]

18. Li, X.S.; Cai, W.W.; An, J.H.; Kim, S.Y.; Nah, J.H.; Yang, D.X.; Piner, R.; Velamakanni, A.; Jung, I.; Tutuc, E.; et al. Large-area synthesis of high-quality and uniform graphene films on copper foils. Science 2009, 324, 1312-1314. [CrossRef] [PubMed]

19. Kang, X.H.; Wang, J.; Wu, H.; Liu, J.; Aksay, I.A.; Lin, Y.H. A graphene-based electrochemical sensor for sensitive detection of paracetamol. Talanta 2010, 81, 754-759. [CrossRef]

20. Wei, W.; Nong, J.; Zhang, G.; Tang, L.; Jiang, X.; Chen, N.; Luo, S.; Lan, G.; Zhu, Y. Graphene-based long-period fiber grating surface plasmon resonance sensor for high-sensitivity gas sensing. Sensors 2016, 17, 2. [CrossRef]

21. Xue, Y.H.; Baek, J.M.; Chen, H.; Qu, J.; Dai, L.M. N-doped graphene nanoribbons as efficient metal-free counter electrodes for disulfide/thiolate redox mediated DSSCs. Nanoscale 2015, 7, 7078-7083. [CrossRef]

22. Yin, H.; Chen, P.W.; Xu, C.X.; Gao, X.; Zhou, Q.; Yang, Z.; Qu, L.T. Shock-wave synthesis of multilayer graphene and nitrogen-doped graphene materials from carbonate. Carbon 2015, 94, 928-935. [CrossRef]

23. Ye, M.H.; Zhang, Z.P.; Zhao, Y.; Qu, L.T. Graphene platforms for smart energy generation and storage. Joule 2018, 2, 245-268. [CrossRef]

24. Syama, S.; Mohanan, P.V. Safety and biocompatibility of graphene: A new generation nanomaterial for biomedical application. Int. J. Biol. Macromol. 2016, 86, 546-555. [CrossRef] [PubMed]

25. Ruse, E.; Buzaglo, M.; Pri-Bar, I.; Shunak, L.; Nadiv, R.; Pevzner, S.; Siton-Mendelson, O.; Skripnyuk, V.M.; Rabkin, E.; Regev, O. Hydrogen storage kinetics: The graphene nanoplatelet size effect. Carbon 2018, 130, 369-376. [CrossRef]

26. Lee, K.E.; Kim, J.E.; Maiti, U.N.; Lim, J.; Hwang, J.O.; Shim, J.; Oh, J.J.; Yun, T.; Kim, S.O. Liquid crystal size selection of large-size graphene oxide for size-dependent $n$-doping and oxygen reduction catalysis. ACS Nano 2014, 8, 9073-9080. [CrossRef] [PubMed] 
27. Zhang, X.; Yan, X.B.; Chen, J.T.; Zhao, J.P. Large-size graphene microsheets as a protective layer for transparent conductive silver nanowire film heaters. Carbon 2014, 69, 437-443. [CrossRef]

28. Geng, X.M.; Guo, Y.F.; Li, D.F.; Li, W.W.; Zhu, C.; Wei, X.F.; Chen, M.L.; Gao, S.; Qiu, S.Q.; Gong, Y.P.; et al. Interlayer catalytic exfoliation realizing scalable production of large-size pristine few-layer graphene. Sci. Rep. 2013, 3, 1134. [CrossRef] [PubMed]

29. Xu, W.; Gong, Y.P.; Liu, L.W.; Qin, H.; Shi, Y.L. Can graphene make better HgCdTe infrared detectors. Nanoscale Res. Lett. 2011, 6, 250. [CrossRef]

30. Ago, H. CVD growth of high-quality single-layer graphene. In Frontiers of Graphene and Carbon Nanotubes; Mastumoto, K., Ed.; Springer: Tokyo, Japan, 2015; pp. 3-20. [CrossRef]

31. Zhang, J.; Hu, P.A.; Wang, X.N.; Wang, Z.L.; Liu, D.Q.; Yang, B.; Cao, W.W. CVD growth of large area and uniform graphene on tilted copper foil for high performance flexible transparent conductive film. J. Mater. Chem. 2012, 35, 18283-18290. [CrossRef]

32. Acik, M.; Chabal, Y.J. A review on thermal exfoliation of graphene oxide. J. Mater. Sci. Res. 2013, 2, 101-112. [CrossRef]

33. Yi, M.; Shen, Z.G. A review on mechanical exfoliation for the scalable production of graphene. J. Mater. Chem. A 2015, 3, 11700-11715. [CrossRef]

34. Soldano, C.; Mahmood, A.; Dujardin, E. Production, properties and potential of graphene. Carbon 2010, 48, 2127-2150. [CrossRef]

35. Gao, X.; Xu, C.X.; Yin, H.; Wang, X.G.; Song, Q.Z.; Chen, P.W. Preparation of graphene by electrical explosion of graphite sticks. Nanoscale 2017, 9, 10639-10646. [CrossRef] [PubMed]

36. Gao, X.; Yokota, N.; Oda, H.; Tanaka, S.; Hokamoto, K.; Chen, P.W.; Xu, M. Preparation of few layer graphene by pulsed discharge in graphite micro-flake suspension. Crystals 2019, 9, 150. [CrossRef]

37. Su, C.Y.; Xu, Y.P.; Zhang, W.J.; Zhao, J.W.; Tang, X.H.; Tsai, C.H.; Li, L.J. Electrical and spectroscopic characterizations of ultra-large reduced graphene oxide monolayers. Chem. Mater. 2009, 21, 5674-5680. [CrossRef]

38. Chen, X.P.; Zhang, L.L.; Chen, S.S. Large area CVD growth of graphene. Synth. Met. 2015, 210, 95-108. [CrossRef]

39. Bae, S.; Kim, H.; Lee, Y.; Xu, X.; Park, J.; Zheng, Y.; Balakrishnan, J.; Lei, T.; Kim, H.R.; Song, Y.I.; et al. Roll-to-roll production of 30-inch graphene films for transparent electrodes. Nat. Nanotechnol. 2010, 5 , 574-578. [CrossRef]

40. Kotov, Y.A. Electric explosion of wires as a method for preparation of nanopowders. J. Nanopart. Res. 2003, 5, 539-550. [CrossRef]

41. Liu, L.C.; Zhang, Q.G.; Zhao, J.P.; Yan, W.Y.; Zhang, L.; Wang, Z.; Tie, W.H. Study on characteristics of nanopowders synthesized by nanosecond electrical explosion of thin aluminum wire in the argon gas. IEEE Trans. Plasma Sci. 2013, 41, 2221-2226. [CrossRef]

42. Wada, N.; Akiyoshi, K.; Morita, K.; Hokamoto, K. Reaction synthesis of several titanium oxides through electrical wire explosion in air and in water. Ceram. Int. 2013, 39, 7927-7933. [CrossRef]

43. Hokamoto, K.; Wada, N.; Tomoshige, R.; Kai, S.; Ujimoto, Y. Synthesis of TiN powders through electrical wire explosion in liquid nitrogen. J. Alloy. Compd. 2009, 485, 573-576. [CrossRef]

44. Tanaka, S.; Bataev, I.; Oda, H.; Hokamoto, K. Synthesis of metastable cubic tungsten carbides by electrical explosion of tungsten wire in liquid paraffin. Adv. Powder Technol. 2018, 29, 2447-2455. [CrossRef]

45. He, L.F.; Shirahata, J.; Suematsu, H.; Nakayama, T.; Suzuki, T.; Jiang, W.; Niihara, K. Synthesis of BN nanosheet/nanotube-Fe nanocomposites by pulsed wire discharge and high-temperature annealing. Mater. Lett. 2014, 117, 120-123. [CrossRef]

46. Lee, D.H.; Kim, J.C.; Shim, H.W.; Kim, D.W. Highly reversible Li storage in hybrid NiO/Ni/graphene nanocomposites prepared by an electrical wire explosion process. ACS Appl. Mater. Interfaces 2014, 6, 137-142. [CrossRef] [PubMed]

47. Gao, X.; Yokota, N.; Oda, H.; Tanaka, S.; Hokamoto, K.; Chen, P.W. One Step Preparation of Fe-FeO-Graphene Nanocomposite through Pulsed Wire Discharge. Crystals 2018, 8, 104. [CrossRef]

48. Kobayashi, R.; Nishimura, S.; Suzuki, T.; Nakayama, T.; Suematsu, H.; Jiang, W.H.; Niihara, K. Pressure dependence of phases in carbon nanosized powders for investigating cooling rate of pulsed wire discharge plasma. Adv. Mater. Res. 2006, 11, 307-310. [CrossRef] 
49. Suematsu, H.; Minami, C.; Kobayashi, R.; Kinemuchi, Y.; Hirata, T.; Hatakeyama, R.; Yang, S.C.; Jiang, W.H.; Yatsui, K. Preparation of fullerene by pulsed wire discharge. Jpn. J. Appl. Phys. 2003, 42, L1028-L1031. [CrossRef]

50. Kobayashi, R.; Nishimura, S.; Suzuki, T.; Suematsu, H.; Jiang, W.H.; Yatsui, K. Synthesis of single-walled carbon nanotubes by pulsed wire discharge. Jpn. J. Appl. Phys. 2005, 44, 742-744. [CrossRef]

51. Baklar, V.Y. Optimization of the synthesis of different carbon allotropes by electric explosion of graphite conductors. Surf. Eng. Appl. Electrochem. 2011, 47, 61-65. [CrossRef]

52. Rud, A.D.; Kuskova, N.I.; Ivaschuk, L.I.; Zelinskaya, G.M.; Biliy, N.M. Structure state of carbon nanomaterials produced by high-energy electric discharge techniques. Fuller. Nanotub. Carbob Nanostruct. 2011, 19, 120-126. [CrossRef]

53. Berger, C.; Song, Z.M.; Li, X.B.; Wu, X.S.; Brown, N.; Naud, C.; Mayou, D.; Li, T.B.; Hass, J.; Marchenkov, A.N.; et al. Electronic confinement and coherence in patterned epitaxial graphene. Science 2006, 312, 1191-1196. [CrossRef] [PubMed]

54. Gayathri, S.; Jayabal, P.; Kottaisamy, M.; Ramakrishnan, V. Synthesis of few layer graphene by direct exfoliation of graphite and a raman spectroscopic study. AIP Adv. 2014, 4, 027116. [CrossRef]

55. Li, M.; Liu, J.; Zhang, X.; Zhou, C.; Munagala, S.P.; Tian, Y.; Ren, J.; Jiang, K. Graphene platelet (GPL)/nickel (Ni) laminate coatings for improved surface properties. Adv. Eng. Mater. 2017, 19, 1600795. [CrossRef]

56. Zhu, L.X.; Zhao, X.; Li, Y.Z.; Yu, X.Y.; Li, C.; Zhang, Q.H. High-quality production of graphene by liquid-phase exfoliation of expanded graphite. Mater. Chem. Phys. 2013, 137, 984-990. [CrossRef]

57. Escobar-Alarcón, L.; Espinosa-Pesqueira, M.E.; Solis-Casados, D.A.; Gonzalo, J.; Solis, J.; Martinez-Orts, M.; Haro-Poniatowski, E. Two-dimensional carbon nanostructures obtained by laser ablation in liquid: Effect of an ultrasonic field. Appl. Phys. A 2018, 124, 141. [CrossRef]

58. Lee, W.; Oh, Y.; Lee, K.E.; Lee, J.U. Contrast enhancement for quantitative image analysis of graphene oxide using optical microscopy for Si-based field effect transistors. Mater. Sci. Semicond. Process. 2015, 39, 521-529. [CrossRef]

59. Nemes-Incze, P.; Osváth, Z.; Kamarás, K.; Biró, L.P. Anomalies in thickness measurements of graphene and few layer graphite crystals by tapping mode atomic force microscopy. Carbon 2008, 46, 1435-1442. [CrossRef]

60. Niu, L.Y.; Li, M.J.; Tao, X.M.; Xie, Z.; Zhou, X.C.; Raju, A.P.A.; Young, R.J.; Zheng, Z.J. Salt-assisted direct exfoliation of graphite into high-quality, large-size, few-layer graphene sheets. Nanoscale 2013, 5, 7202-7208. [CrossRef]

61. Saikia, B.K.; Boruah, R.K.; Gogoi, P.K. A X-ray diffraction analysis on graphene layers of assam coal. J. Chem. Sci. 2009, 121, 103-106. [CrossRef]

62. Malard, L.M.; Pimenta, M.A.; Dresselhaus, G.; Dresselhaus, M.S. Raman spectroscopy in graphene. Phys. Rep. 2009, 473, 51-87. [CrossRef]

63. Eckmann, A.; Felten, A.; Mishchenko, A.; Britnell, L.; Krupke, R.; Novoselov, K.S.; Casiraghi, C. Probing the nature of defects in graphene by raman spectroscopy. Nano Lett. 2012, 12, 3925-3930. [CrossRef] [PubMed]

64. Das, A.; Chakraborty, B.; Sood, A.K. Raman spectroscopy of graphene on different substrates and influence of defects. Bull. Mater. Sci. 2008, 31, 579-584. [CrossRef]

65. Subrahmanyam, K.S.; Panchakarla, L.S.; Govindaraj, A.; Rao, C.N.R. Simple method of preparing graphene flakes by an arc-discharge method. J. Phys. Chem. C 2009, 113, 4257-4259. [CrossRef]

66. Ni, Z.; Wang, Y.; Yu, T.; Shen, Z. Raman spectroscopy and imaging of graphene. Nano Res. 2008, 1, $273-291$. [CrossRef]

67. Zhang, H.B.; Wang, J.W.; Yan, Q.; Zheng, W.G.; Chen, C.; Yu, Z.Z. Vacuum-assisted synthesis of graphene from thermal exfoliation and reduction of graphite oxide. J. Mater. Chem. 2011, 21, 5392-5397. [CrossRef]

68. Parvez, K.; Wu, Z.; Li, R.; Liu, X.; Graf, R.; Feng, X.; Mullen, K. Exfoliation of graphite into graphene in aqueous solutions of inorganic salts. J. Am. Chem. Soc. 2014, 136, 6083-6091. [CrossRef]

69. Hernandez, Y.; Nicolosi, V.; Lotya, M.; Blighe, F.M.; Sun, Z.Y.; De, S.; McGovern, I.T.; Holland, B.; Byrne, M.; Gun'Ko, Y.K.; et al. High-yield production of graphene by liquid-phase exfoliation of graphite. Nat. Nanotechnol. 2008, 3, 563-568. [CrossRef]

(C) 2019 by the authors. Licensee MDPI, Basel, Switzerland. This article is an open access article distributed under the terms and conditions of the Creative Commons Attribution (CC BY) license (http://creativecommons.org/licenses/by/4.0/). 